\title{
Progressive familial intrahepatic cholestasis type 3
}

INSERM

\section{Source}

INSERM. (1999). Orphanet: an online rare disease and orphan drug data base.

Progressive familial intrahepatic cholestasis type 3. ORPHA:79305

Progressive familial intrahepatic cholestasis type 3 (PFIC3), a type of progressive familial intrahepatic cholestasis (PFIC, see this term), is a late-onset hereditary disorder in bile formation that is hepatocellular in origin. Onset may occur from infancy to young adulthood. 